\title{
The Role of Taboos in Solving Contemporary Environmental Degradation in Ghana: The Case of Cape Coast Metro
}

\author{
Emmanuel Abeku Essel \\ Department of Public Administration, National University of Public Service, Budapest, Hungary
}

Email address:

abeabi@yahoo.com,emmanuel.abeku.essel@hallg.uni-nke.hu

\section{To cite this article:}

Emmanuel Abeku Essel. The Role of Taboos in Solving Contemporary Environmental Degradation in Ghana: The Case of Cape Coast Metro. Social Sciences. Vol. 9, No. 4, 2020, pp. 89-97. doi: 10.11648/j.ss.20200904.11

Received: May 6, 2020; Accepted: June 30, 2020; Published: July 13, 2020

\begin{abstract}
One phenomenon which has gained prominence in recent discussions in Ghana has been the role taboos play in addressing environmental degradation. While one group of researchers believes in the conservationist stance, others are of the view that traditional beliefs and practices could play a significant role in preserving the environment for future generations. In the Cape Coast Metropolis, taboos are part of the daily activities of its indigenes, however, the impact environmental taboos exercise, appears to have lessened in comparison with the traditional beliefs. This is probably due to the influence of science and modernity. This paper seeks to find out why the decline in observing environmental taboos amongst the people of Cape Coast is affecting the environment and leading to degradation. Both quantitative and qualitative approaches were used in the analysis. The targeted population were the people of Cape Coast in Ghana and some selected Non-Governmental Organizations which are involved in environmental protection. The study revealed that the people in the area still hold on to their traditions and culture and would not do anything which will have dire consequences on their lives should they break any taboos concerning their environment. In view of this, it is recommended that the local government laws be looked at again to have a fusion of both traditional norms and cultural laws as part of efforts to preserve the environment.
\end{abstract}

Keywords: Taboos, Tradition, Impact, Environmental Degradation

\section{Introduction}

Environmental degradation caused Ghana GH $₫ 42.3$ billion which is 10 percent of its Gross Domestic Product (GDP) in 2016. The country and some other countries across the various continents are currently facing an environmental crisis, which requires an active involvement of all to address these environmental challenges. According to a new report released at the second United Nations Environment Assembly [40], the rate at which environmental degradation and pollution can kill is up to 234 times as compared to many premature deaths caused by conflicts annually, highlighting the devastating effect of an healthy environment in achieving the 2030 Sustainable Development Goals (SDGs). The environment put simply, refers to the natural and physical surroundings and the relationship of people with it. It includes the physical ecosystem which encompasses water, air, structures, land, living organisms, as well as economic, social and cultural conditions.

Activities of humans in the wanton degradation of the environment has reached its apogee something which has stimulated global trepidations for governments and international bodies to seriously begin to enact laws and also have days observed as a means of protecting the earth and the environment. For instance, the "Earth Day of the United Nations Conference on Human Environment" instituted in 1970 and the "International Year of Sanitation, 2008", are but a few days observed to raise awareness and accelerate programs towards achieving the Millennium Development Goals (MDGs) goal seven, that deals with environmental sustainability [39]. The care of the environment has been one phenomenon, which has gained prominence and has revived attention both in academia and in the media landscape during the 20th century [17]. In the words of [30] "there is a global concern to safeguard the increasingly dilapidating environment". The United Nations International Strategy for 
Disaster Reduction as cited by [18] indicated that there is the need to combat environmental degradation in order to minimize or eradicate its threats. Thus, one can say that this is to lessen the limit of the earth to meet social and environmental destinations and needs [18]. It is also evidently clear that, human activities have had an unprecedented and dangerous impact on the global environment [36].

The considerable pressure on the environment in recent times due to rising global population and the attendant problems of urbanization and increased human and industrial activities prompts the use of Indigenous Knowledge Systems (IKS) to combat environmental degradation. The factors that have led to the deterioration of the environment are through pollution, deforestation, improper disposal and management of household and industrial waste, loss of biodiversity and the alteration of ecosystems can be attributed to the relegation and/or abandonment of indigenous knowledge enshrined in the cultural practices of the people such as taboos. [25], stated that, Indigenous Knowledge Systems (IKS) is "local knowledge held by indigenous people or local knowledge that is unique to a given culture or society". It is a form of knowledge that differs from western knowledge systems, which are designed scientifically to lockout feedback from the environment and to avoid natural perturbations. It bestows a moral obligation on applicators of it and thus helps in creating a 'moral economy' [24]. It is worthy to note that, the indigenous knowledge of the Africans and particularly Ghanaians, appealed to their morals and helped in shunning negative behavioral patterns that cause massive havoc to the environment. Indigenous knowledge Systems always focuses on the development of the behavioral patterns of people with the view of changing the way they react to the biodiversity resources in nature.

The relevance of indigenous knowledge systems cannot be overemphasized. Its positive impacts can be seen in every developmental aspect of life [3]. An indigenous person would look at nature and observe its vibrancy and meaning as well as regard it with awe and uncertainty, while a westerner would see nature as an inanimate clock governed by simple universal laws, that behaves as an automation which once programmed will continue to follow the rules inscribed in the program. One of such knowledge systems has been taboos, which somehow may be an ambiguous term and may lack a specific understanding owing to the myriad angles at which one can look at it. Normally, they are seen to involve a prohibition of some activities that are not well known in its formulation. According to [20], a "taboo is a strong social prohibition (ban) against words, objects, actions or discussions that are considered undesirable or offensive by a group, culture, society or community". According to [15], "taboos were most commonly inherited from parents, both mother, and father, and passed down through generations", they further added that, "these generational and bilateral types of taboos tended to be respected and observed by all children and could not be ignored. Breaking a taboo to them, is usually considered objectionable or abhorrent.

[26] in contributing to the phenomenon of taboos also said, some taboo activities or customs are prohibited by law and transgressions may lead to severe penalties. While a few books and articles have been written from the perspective of Indigenous Knowledge and the environment. However, the list is by no means exhaustive. The current study has the potential to open a fresh understanding of the role taboos play in contemporary issues relating to the environment in the day-to-day activities of the people of Cape Coast in the Central Region of Ghana. This paper seeks to find answers to the perceived challenges relating to this, and it will also serve to illuminate some constructive suggestions and issues, in terms of taboos in environmental protection in Ghana. The objective of this paper is but not limited only to highlighting the plight of environmental degradation that is destroying the eco-system in the research area, but also suggested ways of overcoming it. More also, it contributes to local and national perspectives on environmental conservation and protection.

\section{Taboos and the Environment}

Ghana, like many other African countries, is gifted with a very rich culture and tradition. The traditional culture of Ghana stresses a strong relationship with the environment, and in the past, a culturally acceptable environmental management system resulted from parameters and taboos related to water bodies, land, and deep forest. [33], stated that taboo means "an akyiwade; that which is forbidden or prohibited". [37] on the other hand posited that, "taboo is concerned (a) with all the social mechanisms of obedience which have ritual significance; (b) with specific and restrictive behavior in dangerous situations. According to [32], within its historical context, taboo was a sacred term for a set of cultic or religious prohibitions instituted by traditional religious authorities as instruments for moral motivation, guidance, and objectivity for protecting the sanctity of their shrines and the wellbeing of their worshipping communities. Although there are some cultural practices that are peculiar to some towns and villages, in general, they have so many things in common and served the same important purpose of conserving nature. [9], suggests that a clear line must be drawn between the language of taboo, the language of abuse, and the language of swearing. Among the Akan community, the largest ethnic group in Ghana, water bodies and the environment are associated with lesser gods known as "abosom". This is in accordance with the rules laid down by their ancestors and are followed and protected by the traditional priests of the community.

[27], in a study on the role of Okonko society in preserving the Igbo environment noted that for the African, the environment remains a complex reality and also seen in a much more inclusive way in many developed countries. The environment encapsulates lifeforms in both spiritual and physical realms. [27], further adds that the natural environment includes social, religious, linguistic, economic, and other cultural elements. The African see the natural environment as being closely tied to integral human life, and without it, human life may not be sustained [27]. However, [29] says that in the traditional African worldview, the environment embraces the culture of a people (language, 
beliefs, customs, food habits, way of dressing and crafts), including the physical milieu of the people and their natural resources, climate, and human character.

Until the period of industrial revolution and urbanization, indigenous groups in some societies, including the Asantes in Ghana, used cultural practices to conserve forests, which were largely successful [4]. In a study by [5], he indicated that Ghana boasts of numerous forest reserves that are conserved through socio-cultural beliefs by traditional people. The laws and regulations which man instituted concerning the environment were aimed at allowing the Earth to continuously play its mothership role and to enhance the biodiversity. The body of laws and regulations are known as taboos. Each locality, or community, or traditional area had its own sets of taboos. For instance, [8] stated that "an Asante craftsman will endeavor to propitiate certain trees before he cuts them down. He will offer an egg, for example, to the Odum tree, saying, "I am about to cut you down and carve you; do not let me suffer harm". Again, people had to obey the 'Day of Rest' such as Tuesdays and Fridays for fishing along the coast and farming in certain areas in Ghana, respectively as known as taboo-days. People had to obey these taboos since such days had been regarded as ndabone, "bad days" [1] Each locality had its day of rest. The belief was that the spirit of the earth should be allowed to rest. There is a taboo against the clearing of the vegetation right up to the edges of streams and rivers. Farmers were enjoined to leave a strip of land of Abasqfaaduasa, that is, "about 30 metres", which should not be cleared at both sides of streams and rivers. The benefit of this conservation method was quite obvious to any environmentalist.

However, in recent times, mismanagement of the environment in Ghana has been a major issue [2, 13], the cause is both local and international. Locally, people abuse the environment through economic activities as well as negative attitudes towards life in general. Not only is the land degraded and the forest cover eroding quickly, but water bodies too are polluted and wildlife is also facing extinction. Drains are choked with rubbish and filth. The environment is the natural world on which humans, animals, and plants depend, which included water, air, and other things that life in general needs to survive and thrive. The second cause of Ghana's mismanagement of the environment is international, in the sense that Western economic policies encourage the exploitation of raw materials in the developing world at the expense of the environment, to feed Western industries [12, 13 , as cited in 13]. When the quality of the environment is compromised, reduced, or damaged, it can cause serious health hazards to humans, plants, animals, and other life forms. [34], remarked that "it is not nice to poison your neighbor", [35]. For him, pollution represents the failure to satisfy the moral obligation to prevent or minimize harm to our neighbors, both humans and other kinds of life forms. The use of taboos to protect and conserve the environment has been identified in many African countries [19]. Some traditional communities in Ghana have demonstrated this ability to a large extent and proven that indeed, the environment can be managed through the belief in taboos and totems [23].

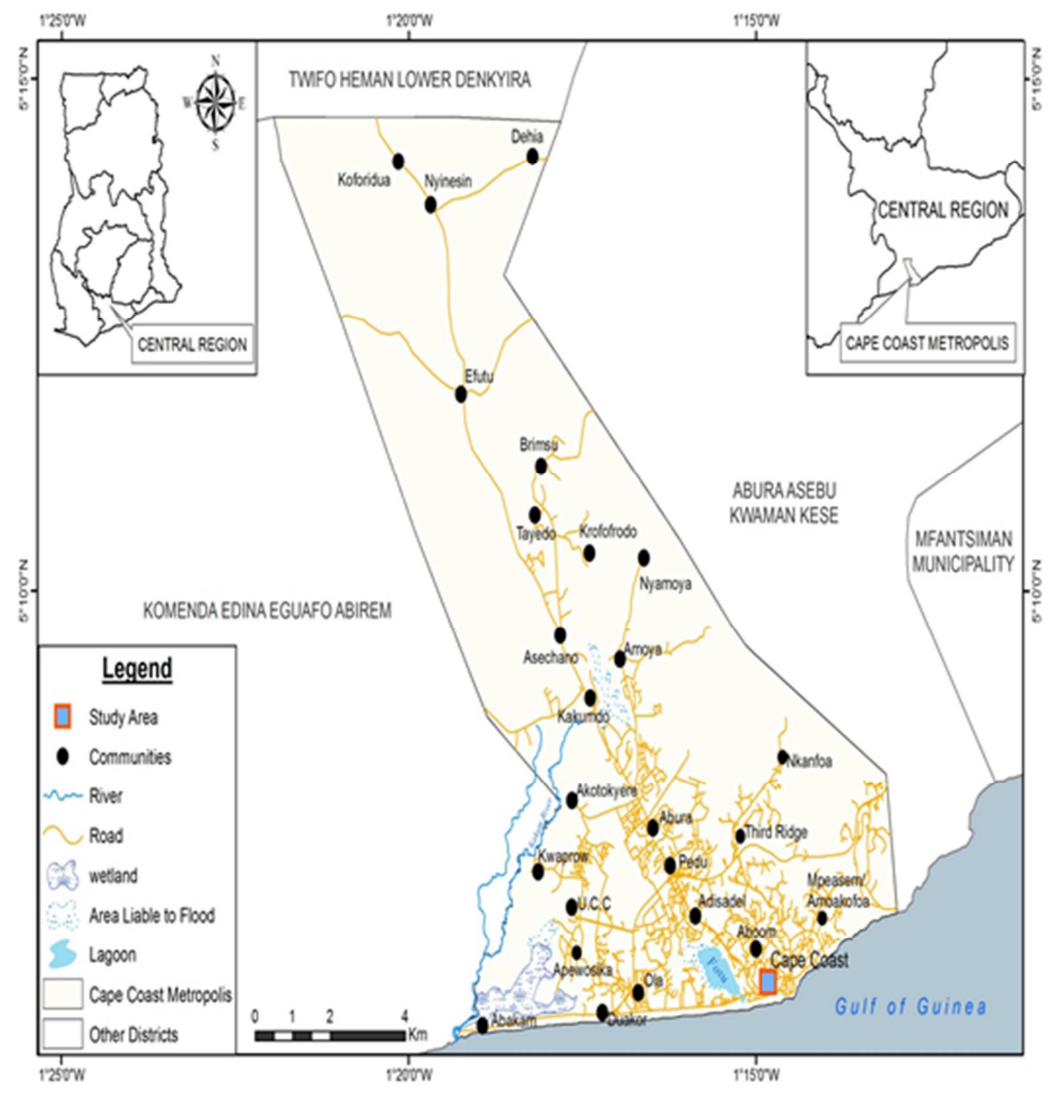

Figure 1. Map of Central Region depicting Cape Coast (Author's own construct, 2020). 


\section{Materials and Methods}

This paper presents a case study on the role taboos play in contemporary times relating to the environment in the day-today activities of the people of Cape Coast in the Central Region of Ghana (Figure 1). Cape Coast is a Metropolis bounded to the South by the Gulf of Guinea, to the West by the Komenda Edina Eguafo Abrem Municipality (KEEA), to the East by the Abura Asebu Kwamankese District (AAK), and to the North by the Twifu Heman Lower Denkyira District. Cape Coast is located on longitude $1^{\circ} 15^{\prime} \mathrm{W}$ and latitude $5^{\circ} 06^{\prime} \mathrm{N}$ and occupies an area of approximately 122 square kilometers. It is the regional capital of the Central Regional of Ghana [14]

The study was undertaken between August to October 2019 in Cape Coast and was taken as a phenomenological study. The mixed-method approached was adopted for the study to find out whether the people are aware of taboos concerning usage of the land and what factors are accounting for the drop in the observation of taboos attached to them leading to a tradition of environmental degradation in the metropolis. A total of 56 respondents participated in the study. The target population were Six (6) Chiefs, Three (3) Asafo " henefo" (Asafo Chiefs), One (1) Traditional Priests, Fifty (43) members of the communities of Cape Coast and three (3) officers of Non-Governmental Organizations (NGO's) whose activities are geared towards environmental protection were purposively selected and sampled for the study. The chiefs including the Asafo "henefo", the traditional priest and the NGOs population were targeted because they are people who are seen as the custodians of the land, which includes the environment and the NGOs role as gatekeepers who are advocating and sensitizing the populace to watch their activities that are affecting the environment respectively.

Table 1. Background information of participants

\begin{tabular}{lll}
\hline \multirow{2}{*}{ Socio-demographic variables } & \multicolumn{2}{l}{ Participants (n=56) } \\
\cline { 2 - 3 } & Freq. & $\mathbf{\%}$ \\
\hline Age (in years) & 17 & 30.3 \\
$20-25$ & 9 & 16.1 \\
$26-30$ & 5 & 9.0 \\
$31-36$ & 8 & 14.2 \\
$37-48$ & 5 & 9.0 \\
$48-54$ & 8 & 14.3 \\
$55-60$ & 4 & 7.1 \\
$61-66$ & & \\
Sex & 22 & 39.0 \\
Female & 34 & 61.0 \\
Male & & \\
Marital status & 10 & 18.0 \\
Single & 2 & 3.5 \\
Divorced & 42 & 75.0 \\
Married & 2 & 3.5 \\
Widow & & \\
Sample & 6 & 10.7 \\
Chiefs & 3 & 5.4 \\
Asafo Henefo & 1 & 1.8 \\
Traditional Priest & 3 & 5.4 \\
NGO's Relations Officers & 43 & 76.7 \\
Members of the Public & &
\end{tabular}

Source: Field study, 2019
Data collection was based on the use of a questionnaire, which consisted of multiple sections, a semi-structured interview guide, and a Focus Group discussion with some of the respondents, particularly the officers of the Conservation Alliance (CA), Centre for Environmental Research and Policy Analysis (CERPA) and Environmental Protection Association of Ghana. The respondents were contacted through letters describing the study and its purpose, making it clear that participation was voluntary since it was an aspect of a Ph.D. program the researcher was undertaking. The study gave room for ethical considerations and these were followed by ensuring participants' privacy and confidentiality regarding the research data and their identity or affiliation. Considering the ethics of the study, before the interviews, all participants were informed of the theme, scope, and objectives of the study. The study provides an abundant opportunity to understand the current situation of the role taboos play on contemporary issues relating to the environment in the day-to-day activities of the people of Cape Coast in the Central Region of Ghana. The study was limited in a number of ways: first, despite the fact that they participated voluntarily, they were relaxed while talking to the researcher and seemed to be less conservative, their reflections may contain some restrictions. Again, participants were from one city and the sample size was small, so they may not be representative enough of the total population of the people in the area. Also, the study's qualitative information or analysis might not have comparative value.

The study used the thematic analysis propounded by [7] to analyze the interviews. This was done to understand the data in detail by repeatedly reading each respondent's answers. In this way, through the analysis, the inherent coherence and integrity of every respondent's story could be respected and maintained, a category theme according to the responses to the various questions was designed to enable the researcher to get a better understanding of participants' explanations and experiences. After a thorough study of all narratives, a comparison of themes was made from the transcripts to know the differences and similarities amongst them. Furthermore, the questionnaire data were analyzed with SPSS Version 21.0 software. Descriptive analysis was presented in terms of frequencies and percentages.

\section{Research Findings and Discussion}

The notion of taboo cannot be confused, for example, with a direct prohibition. A prohibition requires an open and accurate definition, including awareness of the retributions and sanctions or non-compliance, as well as the actions, the moral, or punitive implications that it entails. As regards taboos, one usually starts by making assumptions only, as one cannot clearly determine in every case (and often one receives no guidance either), as to what constitutes a taboo theme in the given situation, context, or community. As a result, if someone breaches a taboo, there will not be any overt discussion or debate about this, consequently whoever breached the taboo 
will get no opportunity to defend themselves - indeed, often they are not even notified about the fact that they had breached a taboo and what that particular taboo was. The discussion of findings initially provides a brief overview of the respondent's perspectives on the key area of decline in the observance of taboos on the environment.

\subsection{Quantitative Analysis}

With regard to age, out of the total respondents of the participants, the minimum average age for respondents was
20 years while the maximum age was 66 years. This clearly showed that the participants are in the position to know what constitutes taboos and their effects on the environment in the community. Almost $75.0 \%$ of the respondents were married. Specifically, the unmarried respondents were mainly 10 (18.0\%), compared to the $2(3.5 \%)$ who are divorced and widows respectively. The study also revealed that $34(61.0 \%)$ of the participant were males as against $22(39.0 \%)$ of their counterparts.

Table 2. Responses on whether taboos existed that protected the environment in Cape Coast.

\begin{tabular}{llllll}
\hline & Strongly Agree & Agree & Disagree & Strongly Disagree & Total \\
\hline$<48$ years old & $12(21.4)$ & 0 & 0 & 0 & $12(21.4)$ \\
$>66$ years old & $44(78.6)$ & 0 & 0 & 0 & $44(78.6)$ \\
Total & $56(100)$ & 0 & 0 & 0 & $56(100)$ \\
\hline
\end{tabular}

*The numbers in parenthesis represent the values in percentage

All the respondents strongly agreed that there were taboos that existed to protect the environment in Cape Coast.

Table 3. Are the taboos protecting the environment still effective or are they compromised by the modernism in Cape Coast

\begin{tabular}{lllll}
\hline & Strongly Effective & Slightly Effective & Slightly Compromised & Strongly Compromised \\
\hline$<48$ years old & $3(5)$ & 0 & $2(3.33)$ & $10(16.67)$ \\
$>66$ years old & $31(78.6)$ & 0 & $4(6.67)$ & $10(16.67)$ \\
\hline
\end{tabular}

*The numbers in parenthesis represent the values in percentage

The study showed that, though taboos are still effective, there had started to be a gradual but increasing compromise in losing its effectiveness.

Table 4. The respondent's view on the cause(s) of loss of respect for traditional laws in Cape Coast.

\begin{tabular}{|c|c|c|c|c|}
\hline & Religion & Development and modernism & Immigration & Others \\
\hline$<48$ years old & $1(6.7)$ & $1(1.67)$ & $10(16.67)$ & 0 \\
\hline$>66$ years old & $34(56.67)$ & $9(15.0)$ & $2(3.33)$ & 0 \\
\hline
\end{tabular}

*The numbers in parenthesis represent the values in percentage

The causes of the loss of respect for the traditional laws protecting the environment in Cape Coast were Religion, Development, and Immigration. The study showed that the effectiveness of the traditional laws (taboos) protecting the environment was not adversely affected by modernism (Table 3) and as such, the people had continued to respect these laws. In recent times, people had become bold at challenging some of the traditional laws as it affected their needs. This boldness could be traceable to Religion, Development, and Immigration (Table 4). Christianity had inspired some communities and as such become apathetic to the traditional laws and taboo practices. Religious and cultural beliefs promoted the sustainable use of natural resources.

\subsection{Qualitative Analysis}

Environmental conservation is not a new phenomenon in Ghana and the world over. Environmental conservation through the indigenous knowledge systems has always been in a commonplace. Environmental conservation is always a common practice with taboos being one strategy among many that are used to conserve and sustainably exploit the natural resources. In the Cape Coast Traditional Area, there are four distinct forms of property rights in natural resources namely state property, private property, non-property (open access), and common property". As a traditional environment conservation strategy, common property is used in Cape Coast to ensure full responsibility and participation by all community members in the management and conservation of resources in their natural environment. For (16), the common property management fails to provide an incentive to conserve the natural environment as each herdsman egoistically competes at raising as many animals as possible.

Tribal groupings headed by Chiefs and supported by the councilors and headmen respected the natural environment. The natural environment was considered common property and was sustainably managed through the wise deployment of indigenous knowledge systems. With these indigenous knowledge systems acting as customary laws, there was informal mutual understanding at all levels of the community in terms of how, when, by what means and by whom resources were harvested and used. Activities like fruit harvesting, cutting down trees, hunting, fishing, grazing, and gathering of other resources from the environment were also regulated by these customary laws enshrined in indigenous 
knowledge systems.

Nature still has much to say and it is high time we, its children, stopped playing deaf (Osabarima Kwesi Atta II, August $31^{\text {st } 2019)}$

While traditional management of the environment by the people was informed by the locals' traditional knowledge forms, the experience that Cape Coasters' go through has led them to despise their own traditional practices and the value as well as rights they previously accorded nature. The modern Cape Coast is therefore not an exception to the conservational crises Africa and the world is facing. Ghana and for that matter, Cape Coast has perpetuated the denigration of traditional conservation practices and disrespect of nature through its national environmental policy, hence the importance of reviving the traditional conservation strategies or at least develop a post-humanities approach that recognises the interrelations between humans and non-humans. [10] and [36] as cited in [38] relate the environmental friendliness of indigenous religion in the African worldview. They opine:

“...Traditional African ecology...is inseparably linked with traditional religion. Environmental protection is sanctioned by the creator God and the ancestors of the land" [10].

"African religious ideas were very much ideas about relationships, whether with other living people, or with spirits of the dead, or with animals, or with cleared land, or with the bush" [35].

Undeniably, "taboo among the Akan's is an obligation and not a choice as most taboos are taken seriously since they are believed to have been imposed by their forebears, traditional rulers, and priests on their behalf and in the general interest of the community" [2]. Unlike ordinary wrongs, taboos are taken more seriously and the mistype of taboos may require blood sacrifices for the pacification and forgiveness of the gods and ancestors who might, according to the traditional belief, otherwise visit their wrath on the living in the form of epidemics, drought, and infertility. On the contrary, though, taboo, is a phenomenon people in the study area do not talk about most often. This is because not anything considered a taboo must be talked about touched and looked at at will. [21].

Based on the results of the study, one can affirm that in the current modern dispensation as the respondent pointed out, taboos are a force to reckon with in the day-to-day life of the people. However, the extent to which it was regarded and the awe surrounding it has dwindled as compared to what pertains in African traditional societies. This phenomenon of the dwindling in the belief and practices of taboos could also be attributed to the extent to which Christianity has also influenced the people and has wiped away their communal living as a unit of a tribe in one location with one common beliefs and practices. Traditional authorities utilized taboos for regulating the ethical use of the environment in view of its resources for ecology and sustainable development. Within the Cape Coast society, taboos serve the purpose of not only preserving trees in areas marked as "sacred" but also various species of animals, fishes, and rivers. For instance, taboos associated with the gods and ancestors prohibit people from exploiting these areas earmarked as sacred. According to Osabarima Kwesi Atta II, "It is also a taboo for a hunter to kill an animal and refuse to eat. In traditional Cape Coast communities, there is a heavy dependence on open wells, and rivers for drinking, cooking, bathing, washing, and agricultural and industrial uses". Another thing that is helped or helping in the fading away of the knowledge of taboos in the day-to-day life of the people in the study area has to do with the mode of passing on knowledge of taboos from one set of generation to the other. It is a common knowledge that in African societies, most traditional knowledge on issues such as taboos are delivered orally. However, owing to contemporary life style and the movement of people especially the younger generation from the local areas, or what could be referred to as their ancestral homes to the cities has taken away the teachings and learning they are to receive on taboos and practice them.

A respondent from Abura, a community in Cape Coast claimed that the environment is being degraded because there are no proper sanctions to those who violate laws concerning the environment. "I remember when we were growing up, we were told that it is the environment that keeps us alive so we must take good care of it, cherish and adore it...now we are not even bothered to know how our environment looks like. We throw things around haphazardly and pollute our water bodies, our life source" (Interview with a respondent, August $\left.31^{\text {st }}, 2019\right)$.

People reckoned that taboos played a significant and positive role in the protection of the environment but that is not the situation now. This is the response I gathered from the PRO of an NGO during the Focus Group Discussion on the current environmental situation in the Cape Coast Traditional Area. This actually represents the environmental reality on the ground today.

The land is now bare and degraded. Almost all our forests are gone and several plants and animal species are no longer here. It was only in a few areas that one could see grasses. But now the place is gradually becoming grassland and most streams and water bodies are drying up and filthy (PRO, FGD, 19 October 2019).

The rate of environmental degradation in Ghana has already been noted. A concern is that, if even governmentprotected areas are being degraded in this way, then the fate of non-protected areas in the country is all the more certain. Some of the interviewees informed the researcher that the heavy encroachment on the only water source in Cape Coast, the 'Baka or Fosu Lagoon' is gradually taken over by mechanics who deposit waste oil into the river body. There used to be a fish sanctuary on the river, which the local people (and tourists to the area) visited to watch during the festive season of the Area. During the data collection phase of the research, it became known that land very close to the river in the study area is overtaken by mechanics. Nana Supi Minah (Interview session, 17 September 2019) was of the view that the river is being destroyed by the activities of the 
mechanics because of bad fishing practices in the Fosu Lagoon, throwing dirty engine oil into the river and using its banks as a makeshift toilet environment where the workers there freely ease themselves into it. He also affirmed that other human activities such as an increase in new human settlement areas lacking the needed social amenities account for the people's wanton aggression on the environment

According to the Public Relations Officer of the Centre for Environmental Research and Policy Analysis (FGD 19 October 2019), the general state of sanitation in the metropolis is a source of worry to many people. The management of both the solid and liquid wastes in the traditional area leaves much to be desired. Heaps of refuse are also a common sight in the Traditional Area. One can sometimes witness animals in the middle of the town feeding on the refuse dumps. Moreover, the majority of people in the municipality rely on public places convenience, but these places are managed very poorly.

The waste disposal sites in the area are also a problem as they are not efficiently managed. These sites become dry and caked during the dry season. Another source of pollution is noise-making. Noise pollution is high, particularly in the Metropolis. This is perpetrated by drinking bars (local pubs), restaurants, music shop operators, and churches, particularly the Pentecostcharismatic groups.

This represents a clear confirmation of one of the concerns shared by most of the key informants that many of the younger generations lack even a basic knowledge of their surroundings, with many failing to understand the consequences of their actions, and only taking an interest in the monetary benefits that they can accrue. This is one of the hurdles that must be crossed in the people's quest to find a lasting solution to the environmental problems that are now confronting the area. Thus, the study area has many environmental problems, but those provided above constitute the major ones.

\section{Discussion}

As already indicated, the combined factors account for the current environmental situation in both Cape Coast and Ghana as a whole. Observing taboos in the study area ensured that there is peaceful co-existence between the visible and the invisible world. As shown in the results, all the respondents from the study area attest to the fact that, the disorder that erupts from breaking of taboo could be prevented by performing certain rituals. In so doing, the harm caused by a beaker of a taboo can either be final nor irreparable. Propitiatory sacrifices could be offered to concern ancestors who seemed to be most affected in the breach of the taboos. This act usually involves slaughtering of animals such as sheep, goats, fowls etc. The study estimated that about $25 \%$ of the community believe in IKS in environmental management and these consist of old aged men and women mainly dominated by traditional leadership members of the community. However, $75 \%$ of the community, which consists of middle and young people, has some negative perceptions of the role of IKS in environmental management.

Enactment of taboo regulations on environmental protection to a large extent has been a bone of contention between the members of the community and the traditional authorities, something that makes it extremely difficult for the traditional authorities to enforce the rules on taboos for the members of the community to obey. Only a few members of the society, especially from the ruling family, tend to follow these taboos. As a result, this has hindered the effectiveness of taboos in environmental protection. Added to that, the traditional authorities maintained that poverty of the traditional area also accounts for the bootlessness of taboos in the regulation of the environment. Not only that, the social, cultural and economic modifications of the people have negatively also swiftly affected the natural resources leading loads of changes in the society. The dilution of cultural beliefs leads to cultural erosion thereby undermining taboos in societies. From the study, it became known that most of the respondents in the traditional leadership bracket were of the view that with the coming into being of science and technology, taboos appear to be having an uncertain chance of continued survival. "There is a big disregard for the observation of taboos owing to science and technology as places held in awe have become a desecrated and no recourse is made to the chiefs and traditional leaders in the area who are the custodians of the land". (Assertion of Aburahene) This confirms [22] assertion that, the new system of heritage management, however, seeks to protect only tangible heritage, and considers modern scientific techniques as the only relevant ways of conservation. There is an interplay between political and economic decisions with regard to resource management and how economic decisions impact on environmental issues in Ghana. The issue of how to balance economic growth against environmental concerns was also identified as a significant problem, and this difficulty is grounded in the fact that economic considerations are infused in all areas of Ghana's political decision-making [11]. The study revealed that, the approaches used in the past to deal with challenges on the environment brought to the fore the persistent demand for putting in place the needed checks to deal with the danger of environmental degradation.

\section{Conclusion}

Result of recent traditional laws and policy reforms indicate that nations are seeking the overall goal of ecologically sustainable development and ecological integrity through the improvement of environmental laws and policies aimed at land degradation management and forest conservation [6]. The study established that taboos are part and parcel of the life of the people of Cape Coast. These have been handed over to them by their parents in the form of oral tradition, events that have happened around them to the effect that, those events had happened because of the people not adhering to the taboos. The revelation in the decline on the observation of taboos provides the means for the powers that 
be to find means based on the authority in the constrictions given to the agents of governance to find means to how they can have this enforced to have the people follow the taboos regarding the environment to save it.

To help curb the problem of environmental degradation, the Cape Coast Traditional Council must institute a policy fashioned along the line of the Assin Kushea principle. Where the Traditional Council has instituted a law and has outlawed indiscriminate disposal of waste in the town. Again in order for the citizenry not to have any excuse of so ever, such as there are no proper places to dispose of waste, the traditional council must through the help of the metropolitan assembly provide the people with proper disposable waste bins displayed at vantage places, and also ensure that households are provided with proper places of convenience to avoid the use of the Fosu Lagoon and the beaches as places of convenience.

The Traditional Chiefs are well respected and as noted by Okyenhene, Osagyefo Amoatia Ofori Panyin, "we as chiefs, by virtue of our close-knit relationship with the people, are uniquely placed to become the perfect vehicles for modernization". One can further say that there is the need to integrate the cultural and traditional values into modern government and society. He also added that there is the need for a fusion of traditional and modern forms of justice and adoption of a decentralized system of government, noting that it will strengthen the chieftaincy institution to enforce laws as per the norms and culture of the country [31]. The Chiefs are the heart to the society, the heartbeat of the society and if they are empowered, they will be in a position to transform their communities [28]

Chiefs continue to hold a symbolic cultural role in most African countries, but in this essay, the argument has been that through the consolidation of the modern nation-state, their role has been transformed. It is worthy to note that as a way of educating the younger generation to also know their culture and traditions the Ministry of Education and the Ghana Education Service should consider an introduction of the study of rituals and taboos in the school curricula at all levels of education. Owing to the fact that the main means of learning about taboos is through oral tradition, it will not be out of place for scholars in African Traditional Religion and Philosophy, to begin to love and rigorously collect taboos from the various traditional areas analyze and have them codified for the consumption of the citizenry so as to enable them to know their limitations or otherwise in the face of taboos and its implication on the environment.

\section{References}

[1] Abayie-Boaten, N. B (1993). Notes on Akwasidae: A Traditional Festival of the Asante in Research Review (Supplement No. 6).

[2] Abayie-Boaten, B. (1998). Traditional Conservation Practices: Ghana's Example. Research Review (NS) 14 (1), 42-51.

[3] Adom, D. (2016). Asante indigenous knowledge systems:
Repositories of conservation ethics For Ghana's biodiversity. Paper presented at Conference: Sub-Sahara Indigenous Knowledge and New Discoveries in the New Millennium: Interdisciplinary Approach, At Uthman Danfodio University, Sokoto, PTF I Hall, Sokoto, Sokoto State, Nigeria.

[4] Anane, M. (2015). Religion and conservation in Ghana. Retrieved from: https://www.unngls.org/index.php/23publications/policy-booklets/236-religion-and-conservationin-ghana-by-mike-anane

[5] Asante, E. A., Ababio, S. \& Boadu, K. B., (2017) The Use of Indigenous Cultural Practices by the Ashantis for the Conservation of Forests in Ghana SAGE Open January-March 2017: 1-7 https://journals.sagepub.com/home/sgo Retrieved 6th April 2020.

[6] Benjamin, J. R. (2006) Environment law for sustainability. Sustainability, 26, 1-18.

[7] Braun, V., \& Clarke, V. (2006). Using thematic analysis in psychology. Qualitative Research in Psychology, 3 (2), 77 101.

[8] Busia, K. A. (1954). The Ashanti of the Gold Coast. In Daryll Forde (Ed). African Worlds Studies in the Cosmological Ideas and the Social Values of African Peoples. London: OUP.

[9] Crystal, D. (1995). Cambridge Encyclopedia of the English Language. Cambridge: Cambridge University Press.

[10] Daneel, M. L (2001). African earth keepers: Wholistic interfaith mission. Maryknoll, N. Y.: Orbis Books.

[11] Drazen, A. (2000). Political economy in macroeconomics. Princeton: Princeton University Press.

[12] Gasper, D. (2004). The Ethics of Development. Edinburg University Press, Edinburg.

[13] Gedzi, V. S., Dumbe, Y. \& Eshun, G. (2016). Environmental reviews and case studies: Religious resources and environmental management in Ghana. Environmental Practice $18,137-147$.

[14] Ghana Statistical Service (2010) Population and Housing Census report http://www2.statsghana.gov.gh/docfiles/2010_District_Report/ Central/Cape\%20Coast.pdf Retrieved 20 March 2020.

[15] Golden, C. D., and J. Comaroff. 2015. Effects of social change on wildlife consumption Taboos in northeastern Madagascar. Ecology and Society 20 (2), 41.

[16] Hardin, G. (1968). The tragedy of the commons. In Baden, A., and Noonan, D. S. (Eds.) 1998. Managing the commons. Bloomington: Indiana University Press.

[17] Johnston, R. S. (1997). Geography and geographers. London: Smithsonian Institute Press.

[18] Kanene, K. M., (2016). Indigenous practices of environmental sustainability in the Tonga community of southern Zambia, Jàmbá. Journal of Disaster Risk Studies 8 (1), a331.

[19] Khan, A. W., Ahmad, S. A., Sayed, M. H. S. U., Hadi, S. A., Khan, M. H., Jalil, M. A., Ahmed, R., \& Faruquee, M. H. (1997). Arsenic Contamination in Ground Water and Its Effects on Human Health with Particular Reference to Bangladesh. Journal of Preventive \& Social Medicine 16 (1): 65-73. 
[20] Khan, M. K. \& Parvaiz, A. (2010). A Descriptive Analysis of Diminishing Linguistic Taboos in Pakistan. In Language in India: Strength for Today and Bright Hope for Tomorrow, 10, 1930-2940.

[21] Madu, S. N (2002). Health Complaints of High School Students in the Northern Province and Taboo Themes in their Families. South African Journal of Education, 22 (1), 65-69.

[22] Maradze, J. (2003). Back to the old school? Revival of traditional management systems in Zimbabwe. Papers from the 14th General Assembly and Scientific Symposium of ICOMOS, Victoria Falls.

[23] Marfo, C., (ed.) (2008). Reflections on Religion and Science. Kumasi, Ghana: KNUST Printing Press.

[24] Mojaafryka (2013). Taboos http://mojaafryka.weebly.com/taboos.html Retrieved 20th March 2020

[25] Materer, S., Valdivia, C., \& Gilles, J. (2002). Indigenous Knowledge Systems: Characteristics and importance to climatic uncertainty. Department of Agricultural Economics Working Paper No. AEWP 2001-2003. Columbia: University of Missouri.

[26] Miller, D. (1999). Traditional African Worldviews from a Cosmovision Perspectives in Food for Thought: Ancient Visions and New Experiments of Rural People. London: Zed Books.

[27] Nwosu, P. U. (2010). The Role of Okonko society in Preserving Igbo Environment. Journal of Human Ecology, 31 (1), 59-64.

[28] Nyamekye, E. K. (2020) "What is Next", A Religious Programme aired on GTV and Pent TV On $29^{\text {th }}$ February, 2020.

[29] Obeng. E. A. (1991). The religious experience and the environment: Implication for religious understanding. Journal of African religion and philosophy, 2 (1), 121-126.
[30] Obiora, A. C. \&Emeka, E. E. (2015). African indigenous knowledge system and environmental sustainability. International Journal of Environmental Protection and Policy 3 (4), 88-96.

[31] Ofori Panyin Amota (2010). Chiefs and the Traditional Authorities and their Role in the Democratic Orde and Governance. Constitutional Series. The Institute of Academic Affairs, Accra.

[32] Omobala, O. C. (2013). An Overview of Taboo and Superstition among the Yoruba of Southwest of Nigeria. Rome: University of Rome.

[33] Osei, J. (2006). The Value of Taboos for Biodiversity and Sustainable Development. Retrieved from: www.jsdafrica.com/jsda/fall2006/pdf/Arc

[34] Pussmore, J. (1980). Man's responsibility for nature (2ed). London: Duckworth.

[35] Ranger, T. O. (1988). African Traditional Religion. In Stewart Sutherland and Peter Clarke (Eds). The World's Religions: The Study of Religion, Traditional, and New Religion. London: Routledge, pp. 106-14.

[36] Rosa, E. A., Diekmann, A., Dietz, T., \& Jaeger, C. (2010). Human footprints on the global environment: threats to sustainability. Cambridge, Massachusetts, London: The MIT Press.

[37] Steiner, F. (1956). Taboo. London: Cohen \&West Ltd.

[38] Taringa, N (2006). How environmental is African Traditional Religion? Leiden: Koninklijke Brill NV.

[39] United Nations (2007) MDG Goal 7: Ensure environmental sustainability https://www.mdgmonitor.org/mdg-7-ensureenvironmental-sustainability/

[40] United Nation Environment Assembly https://environmentassembly.unenvironment.org/unea (2016) Retrieved 18th February, 2020. 